\title{
KEBAKARAN HUTAN INDONESIA DAN UPAYA \\ PENANGGULANGANNYA
}

\author{
Rahimah \\ 2010128220022@mhs.ulm.ac.id \\ Prodi Pendidikan Ilmu Pengetahuan Sosial, FKIP Universitas Lambung Mangkurat
}

\begin{abstract}
Abstrak
Kebakaran hutan ialah bencana yang kerap terjadi di negara Indonesia pada musim kering atau kemarau. Kebakaran ini sangat merugikan di berbagai sektor kehidupan masyarakat. Misalnya berdampak di sektor kesehatan, ekologi, ekonomi dan sosial. Dari hal demikian perlu adanya upaya dan cara penanggulangannya agar kebakaran ini bisa teratasi. Perlu juga adanya kerja sama yang dilakukan baik itu pemerintah maupun masyarakat dalam penanggulangannya. Secara khususnya artikel ini bertujuan agar masyarakat Indonesia sadar atas perilakunya dalam melakukan pembakaran itu berbahaya dan dampaknya bukan main bagi kehidupan ini. Pada penulisan ini menggunakan metode studi kepustakaan yang dimana hasil penulisannya diperoleh dari berbagai sumber artikel dan jurnal yang relevan dan juga di analisa kejelekannya. Lalu selanjutnya membuat dalam sebuah penulisan artikel. Hasil kepenulisan dari studi kepustakaan ini adalah kebakaran hutan yang terjadi di Indonesia yang mana banyak disebabkan oleh beberapa faktor dan hal ini berdampak bagi makhluk hidup serta bentuk upaya dalam penanggulangannya. dengan hal ini maka kita dapat memahami bahwa terjadinya kebakaran akan menimbulkan bencana yang merugikan.
\end{abstract}

Kata kunci: kebakaran, Indonesia, penanggulangannya

\section{PENDAHULUAN}

Kebakaran hutan bencana yang kerap kali ada di negara Indonesia, apalagi pada musim kering atau kemarau (Arisanty,.D, 2016). Kebakaran ini tentunya akan berakibat pada beberapa sektor kesehatan, ekologi, ekonomi dan sosial. Dari fakta tersebut pula kebakaran ini mengakibatkan kasus asap yang berlebih dan tentunya sangat membahayakan dan merugikan bagi masyarakat. Dari kebakaran ini terjadi tentunya ada dua pemicu yang utama dan ini dipicu oleh alamnya itu sendiri dan juga aktivitas dari manusianya sendiri. Pelaku yang tidak mau mengaku dan tanggung jawab dari apa yang diperbuatnya dalam melakukan pembakaran lahan dalam membuka kawasan akan berakibat yang besar. Mereka melakukan hal demikian karena alasan biaya, waktu dan mudah dalam melakukannya (Septianingrum, 2018),

Pada tahun 1997 dan 1998 mengalami kebakaran yang parah dan itu berakibat sangat buruk baik bagi Indonesia maupun internasional. Kebakaran yang terjadi ini akan 
menarik bagi internasional dalam hal lingkungan dan ekonomi. Karena terjadinya dampak yang global yang mengalami pencemaran udara yang hebat dan sangat menghambat aktivitas dan kesehatan masyarakat. Tidak hanya Indonesia namun negara yang berdekatan seperti Singapura, Brunei Darussalam, Malaysia dan lainnya yang terkena imbasnya juga terancam atas mengganggunya masyarakat mereka karena terhambatnya transportasi udara antar negara (Rasyid, 2019).

Berbagai kebijakan pun dilakukan dalam upaya menanggulangi kebakaran tersebut. Namun tentunya sangat sulit dilakukan secara signifikan. Kebakaran pun sudah sering terjadi namun kurang sadarnya dari masyarakat pun masih saja ada. Oleh sebab itu perlu adanya kerjasama yang dilakukan baik itu dari pemerintah dan juga masyarakatnya agar hal demikian teratasi dan tidak terjadi lagi (Septianingrum, 2018). Hal demikian tentunya sangat merugikan pemerintah dan masyarakat yang ada. Sehingga dalam penulisan ini bertujuan agar masyarakat Indonesia sadar akan bahayanya yang disebabkan oleh kebakaran ini sangat merugikan dan hal ini bukan main akibatnya dan tanpa mereka sadari hal yang dianggap remeh tersebut juga bisa menjadi faktor penyebab kebakaran.

\section{METODE}

Jenis penulisan yang dilakukan pada artikel ini adalah studi kepustakaan ataupun kebanyakan orang mengatakan literature review yang dipaparkan secara deskriptif mengenai permasalahan lingkungan hidup yaitu kebakaran hutan yang ada di Indonesia dan upaya yang dilakukan dalam penanggulangannya (Arisanty, D.,\& Mutiani,M, 2021). Dan materi yang diambil pada penulisan ini bersumber dari artikel dan jurnal yang relevan sesuai apa yang dibahas. Objek dari penulisan ini adanya permasalahan lingkungan hidup yang sering terjadi yaitu kebakaran. Pada penulisan ini menggunakan teknik yang diawali dari mengumpulkan beberapa sumber artikel dan jurnal yang relevan untuk diangkat. Selanjutnya sumber tadi di kaji, di analisa, dan di telaah kerelevanannya dengan apa topik yang dibahas. Data yang sudah terkumpul tadi di analisis dan disusun secara deskriptif dalam penulisan artikel sesuai apa yang telah ingin di angkat.

\section{PEMBAHASAN}

Hutan mempunyai banyak sumber dari alamnya yang besar dan nilainya pun tak terhingga. Di dalamnya banyak sekali aneka ragam hayati sebagai pengatur dari tata air, sumber plasma nutfah pencegah erosi ataupun banjir, penghasil kayu ataupun non-kayu, melindungi alam hayatinya sebagai kebudayaan, dan lainnya (Rasyid, 2019). 
Demikianlah dari pemanfaatan dan perlindungan hutan ini diatur dalam UU No. 5 tahun 1990, UU No. 4 tahun 1999, UUD 1945, UU No. 32 tahun 2009, PP NO. 28 tahun 1985 dan ada juga beberapa keputusan Menteri Kehutanan serta keputusan dari Dirjen PHPA dan Dirjen Pengusahaan Hutan. Kebakaran adalah terjadinya sesuatu yang terbakar dan hal tersebut akan menimbulkan bahaya dan akan datangnya bencana. Kebakaran ini bisa terjadi disebabkan pembakaran yang tidak sengaja, pembukaan lahan dengan api, pembalakan hutan, dan lainnya (Rasyid, 2019).

Kebakaran hutan ini terjadi juga menjadi perhatian secara internasional atas isu ekonomi dan lingkungan yang disebabkan kebakaran. Di penghujung tahun 1997 dan di pengawalan tahun 1998 yang dimana waktu itu api kebakaran melumpuhkan jutaan hektar lahan hutan tropis Indonesia (Rasyid, 2019). Kejadian kebakaran berakibat bagi lintasan panjang di pulau Kalimantan dan Sumatera yang membentuk kabutan asap yang sangat membahayakan keamanan perjalanan dan ekonomi yang dirugikan sangat besar di negara tetangga (Tahulele, 2019).

Sering sekali terjadi kebakaran hutan dan lahan ini karena faktor alamnya maupun faktor dari ulah manusianya sendiri. Kondisi bahan bakar yang rentan akan terjadinya kebakaran karena kadar air yang rendah dan tersedianya bahan bakar yang berlanjut (Arisanty,D., Haris,M.A., Kumalawati,R., 2017). Faktor iklim pun seperti curah hujan, angin yang rendah dan suhu yang panas maka akan menambah kerentanan pun terjadi. Suhu sinar matahari yang tinggi maka secara tidak langsung akan menyebabkan bahan bakar seperti ranting, dahan dan daun mudah terbakar serta angin yang mempengaruhi keringnya bahan bakar maka akan semakin cepat pula api yang membakar menjalar (Septianingrum, 2018).

Berikut faktor sosial budaya masyarakat yang sering dihadapi terjadinya kebakaran (Rasyid, 2019), antara lain:

a. Pembukaan lahan dengan api

Hal ini sering terjadi dilakukan masyarakat dalam pembukaan lahan karena dianggap mudah dan cepat dalam membuka. Selain itu juga, masyarakat dengan acara ini maka tidak akan banyak dalam mengeluarkan biaya (Rasyid, 2019).

b. Pembalakan liar 
Adanya kegiatan pembalakan liar yang dilakukan masyarakat maka akan menjadikan lahan setempat kritis dan tingkat rawannya terhadap kebakaran akan semakin tinggi. Adanya kegiatan pembakaran yang dilakukan maka akan mudah merambat ke area lahan yang kritis tadi. Adanya pembalakan liar ini akan meninggalkan daun, cabang dan ranting yang akan menambah potensi kebakaran pada musim kebakaran dan menimbulkan hutan tersebut terbakar (Septianingrum, 2018).

c. Hijauan makanan ternak (HMT)

Masyarakat sekitar yang hidup dekat dengan sekitar hutan maka tentu erat kaitannya dengan peternakan dan pengembala. Dengan melakukan peternakan maka akan menambah penghasilan dari warga masyarakat dalam hidupnya. Kebutuhan pakan ternak ini maka harus dipenuhi (Rasyid, 2019). Biasanya masyarakat akan melakukan pembakaran di area lahan yang sudah tidak produktif dan terpakai. Hal demikian karena setelah melakukan pembakaran di area lahan tadi maka akan menimbulkan rerumputan yang baru kualitasnya pun bagus. Namun tanpa mereka sadari hal ini maka akan menjadi salah satu faktor terjadinya kebakaran lahan dan hutan karena melakukan pembakaran tanpa adanya pengawasan dari seseorang tersebut.

d. Perambahan hutan

Perambahan hutan yang dilakukan masyarakat juga menjadi faktor penyebab terjadinya kebakaran. Perambahan ini terjadi migrasinya penduduk dalam kawasan hutan. Semakin lamanya kehidupan ini maka akan semakin meningkatnya pertumbuhan penduduk dan semakin banyaknya pula kebutuhan yang diperlukan (Arisanty,D., Haris,M.A., Kumalawati,R., 2017).

Tentunya masyarakat yang ingin menambah kebutuhan tersebut akan melakukan penambahan luas kawasan garapan baik itu pertanian maupun perkebunan dalam pemenuhan kebutuhan. Kebanyakan dari masyarakat melakukan perambahan lahan ini dan membuka lahan yang dijadikan lahan perkebunan dan juga lahan yang dijadikan pertanian dengan membakar lahan tersebut disana. Selain karena mudah dan cepat hal ini dilakukan karena tidak memerlukan biaya yang dikeluarkan banyak (Yusuf, A., Hapsoh, H., Siregar, S. H., \& Nurrochmat, D. R. 2018). Kepadatan penduduk juga menjadi faktor terbakar karena semakin banyaknya penduduk yang 
terus saja membuka lahan untuk kebutuhan (Arisanty, D., Anis, MZA, Putro, HPN., 2021).

e. Kurang sadarnya manusia dan ketidaksengajaan

Kurang sadarnya manusia juga akan menimbulkan kebakaran lahan dan hutan terjadi. Biasanya aktivitas manusia yang tidak sadar dan tidak sengajanya manusia ialah perilaku manusia adalah aktivitas manusia yang bisa mengambil rotan dan bekerja sambil merokok. Tanpa sadar mereka akan membuang puntung rokok tadi sembarang apalagi ditambah kawasannya yang rawan akan terjadi kebakaran (Rasyid, 2019).

f. Kurangnya penegakan hukum yang dilakukan

Penegakan hukum yang kurang terhadap pelaku kebakaran ini maka tentunya tidak akan membuat pelaku tersebut jera. Pelaku akan tetap melakukan hal yang sama walaupun kebakaran ini tidak merugikan mereka sendiri.

Kerugian yang disebabkan oleh pembakaran ataupun kebakaran ini besar bagi manusianya sendiri maupun kehidupan lainnya. Apalagi kerugian yang ditimbulkan tersebut malah merenggut korban jiwa. Dampak kebakaran dan pembakaran ini(Tuhulele, 2019), yaitu:

a. Dampak bagi kesehatan

Kabut asap yang ditimbulkan dari kebakaran menimbulkan dampak yang serius. Asap yang disebabkan akan mengganggu sistem pernapasan manusia. Asap dari kebakaran ini akan menimbulkan gangguan pada masyarakat yang miskin, anak-anak dan ibu hamil seperti terjadinya infeksi saluran pernapasan, bronchitis, asma bronkial, iritasi mata, iritasi kulit dan pneumonia (Septianingrum, 2019). Apalagi kegiatan manusia yang dilakukan diluar ruangan. Selain itu juga kabut ini akan membuat jarak pandang seseorang akan terbatas dan kecelakaan akan mungkin saja terjadi. Dampak dari kabut ini juga mengakibatkan jalur lalu lintas penerbangan mengalami gangguan bahkan sampai tidak melakukan penerbangan (Septianingrum, 2018).

b. Dampak ekonomis

Dampak langsung yang diakibatkan terjadinya kebakaran dan pembakaran ini secara ekonomis akan berimbas ke hilangnya hasil hutan kayu maupun non-kayu dan hilang ya atas beraneka ragamnya hayati dan lainnya (Rahmini, N., \& Sofiana, Y. 2021). Adapun dampak dari pembakaran dan kebakaran ini yang bisa dihitung seperti rugi yang 
dirasakan oleh pelaku perkebunan, pertanian, mahalnya obat dan anjloknya pendapatan bidang pariwisata (Rasyid, 2019).

Dilakukannya pemadaman yang sulit akan membuat anggaran dana yang dikeluarkan pemerintah juga akan bertambah. Tidak hanya itu saja, jadwal transportasi yang dijadwalkan juga akan mengalami kebatalan, Jika hal demikian tetap sulit untuk dilakukan maka dengan itu hujan buatan pun dari memberikan garam di awan akan dilakukan pada daerah yang terbakar tidak sesuai disebabkan dari cepatnya angina dan iklim yang terjadi secara tiba-tiba (Septianingrum, 2018).

c. Dampak ekologi

Apabila hutan dan lahan tersebut terbakar maka akan membuat beberapa fungsi dari hutan tersebut akan berkurang dan bisa saja hilang. Hal ini berdampak pada sistem ekologi di hutan akan rusaknya produksi dari bahan organic, siklusnya hidrologi, siklus dari unsur hara, suksesi alami dan proses pembentukan lahan (Rasyid. 2019). Terjadinya kebakaran juga akan berdampak pada merosotnya fungsi dari hutan sebagai perosot karbon dan pengatur iklim. Kerugian lainnya pada dampak ekologi ini yaitu berkurangnya daerah hutan dan tidak tersedianya lagi udara yang sehat atas hasil dari vegetasi hutan (Septianingrum, 2018).

d. Dampak sosial

Dampak yang diakibatkan terjadinya kebakaran hutan ini akan menimbulkan kabut asap yang akan membuat dampak bagi kehidupan. Terganggunya kegiatan manusia di luar ruangan juga tentunya akan menghambat dalam perekonomian mereka. Kegiatan sekolah dan jual beli di pasar pun juga akan terganggu karena kabut asap ini. Hal ini akan membuat para keluarga yang berpenghasilan sedikit dan hanya mencari uang dalam perharinya juga akan mengalami pemerosotan (Septianingrum, 2018).

Menghilangnya mata pencaharian bagi masyarakat yang tinggal sekitar hutan pun akan merasakan dampaknya. Apalagi bagi masyarakat sekitar yang biasanya tergantung di alamnya maka akan berdampak sekali bagi mereka dan keluarga dalam pemenuhan kebutuhan kehidupan sehari-hari. Misalnya masyarakat yang berkebun di hutan dan kebakaran tersebut merambat ke area lahan mereka maka mereka akan hilang pendapatan dan juga pemenuhan kebutuhan pun akan sulit (Septianingrum, 2018).

Upaya yang dilakukan dalam pencegahan kebakaran hutan ini telah dilaksanakan dengan berbagai ditetapkannya lembaga. Misalnya Lembaga non Struktural seperti 
Pusdalkarhutda, Satlak juga Brigade-Brigade pemadaman kebakaran di masing hutan yang terjadi. Selain melaksanakan pencegahan pemerintah juga perlu melakukan penanggulangannya dalam berbagai aktivitas yang berupaya dalam penanggulannya. Pemerintah juga melakukan pemberdayaan posko dari kebakaran di semua tingkatan. Pemerintah juga melakukan pembinaan kepada masyarakat (Riyani, Fahrurazi, \& Ariyanto, 2020).

Namun dari beberapa yang dilakukan pemerintah itu masih belum saja berjalan secara optimal disebabkan adanya beberapa faktor. Faktor yang dihadapinya ialah kemiskinan dan ketidakadilan bagi masyarakat yang berada di pinggiran ataupun di pedalaman kawasan hutan. Rasa sadar masyarakat pun juga masih kurang betapa bahayanya yang diakibatkan oleh adanya pembakaran dan kebakaran ini. Pendidikan yang belum memadai baik itu formal maupun nonformal pun juga belum sepenuhnya memadai (Mutiani, 2017).

Agar optimalnya upaya dari pencegahan dan penanggulan terjadinya kebakaran dini maka diperlukan (Septianingrum, 2018), antara lain:

a) Melakukan penyebaran peringatan secara dini melalui media yang ada. Misalnya bisa melalui media cetak, elektronik, dan lainnya kepada masyarakat berkenaan dengan keadaan musim sekarang yang kemarau dan kering bahwa akan berpotensi terjadinya kebakaran. Dengan demikian masyarakat akan lebih berhati-hati dan tidak sembarang dalam melakukan pembakaran meskipun kecil yang dilakukan (Tahulele, 2019).

b) Memantau area yang mudah dan rawan terjadinya kebakaran. Melakukan pemantauan ini maka akan masyarakat yang mau melakukan bisa dicegah dan diberi teguran (Septianingrum, 2018).

c) Menyebarluaskan peringatan untuk larangan melakukan pembakaran (Cahyono, S. A., Warsito, S. P., Andayani, W., \& Darwanto, D. H., 2016).

d) Memberikan fasilitas yang lengkap dalam upaya pemadaman kebakaran apabila terjadi.

e) Memberikan sosialisasi kesadaran kepada masyarakat tentang kebakaran ini apalagi bagi masyarakat yang tinggal di pedalaman (Rahman, A. M., Mutiani, M.,\& Putra, M, A, H., 2019). 
f) Meningkatkan pelatihan bagi masyarakat dengan melakukan teknik yang ramah lingkungan. Misalnya memberikan teknik zero burning. Pada teknik ini dilakukannya sebuah metode dalam melakukan pembersihan lahan dengan melakukan penebangan tegakan pohon tua, kemudian dilakukan cabik-cabik menjadi bagian kecil lalu ditimbun dan tinggalkan agar mengurai dan membusuk dengan alamiah (Sabrina, A. M. 2016).

g) Penegakan hukum yang harus dilakukan bagi pelaku pembakaran agar membuat pelaku tersebut menyesal dan jera (Juliani, J. 2018).

\section{SIMPULAN}

Kebakaran adalah terjadinya suatu bencana yang merugikan manusia dan makhluk hidup lainnya. Faktor dari penyebab terjadinya kebakaran ini disebabkan oleh manusia itu sendiri dan juga alam. Faktor yang terjadi karena manusia itu sendiri antara lain pembukaan lahan dengan api, pembalakan liar, hujauan makan ternah (HMT), perambahan hutan, rasa kurang sadarnya manusia dan kurangnya penegakan hukum yang dilaksanakan. Hal demikian seringkali menjadi penyebab kebakaran itu terjadi terkhususnya di Indonesia.

Dari adanya kebakaran hutan ini maka akan berdampak sekali bagi kehidupan masyarakat yang akan merugikan. Dampak yang ditimbulkan dari kebakaran ini bisa berdampak pada sektor kesehatan, sektor ekologi, sektor ekonomi dan berdampak di sektor sosial. Pemerintah melakukan upaya penanggulangan dengan membangun kelembagaan kebakaran. Dari hal tersebut perlu adanya pengoptimalan yang dilakukan seperti melakukan penyebaran secara dini kepada masyarakat, memantau area yang rentan terjadi kebakaran, melakukan penyebaran larangan membakar, memberikan fasilitas yang lengkap, memberikan pembinaan, melakukan pelatihan teknik zero burning dan juga penegakan hukum yang kuat. Oleh sebab itu, tidak hanya pemerintah yang berperan. Perlu adanya kerjasama yang keras antara pemerintah dan juga masyarakat.

\section{DAFTAR PUSTAKA}

Arisanty, D., Haris, M. A., \& Kumalawati, R. (2017). Identifikasi Faktor-Faktor Kerentanan terhadap Kebakaran Hutan dan Lahan di Kecamatan Cintapuri Darussalam Kabupaten Banjar. Jurnal Pendidikan Geografi, 24. 
Arisanty, D., Anis, M. Z. A., Putro, H. P. N., Hastuti, K. P., \& Angriani, P. (2021, February). Social Vulnerability of Land Fires in Banjarbaru. In The 2nd International Conference on Social Sciences Education (ICSSE 2020) (pp. 262265). Atlantis Press

Cahyono, S. A., Warsito, S. P., Andayani, W., \& Darwanto, D. H. (2016). Faktor-faktor yang mempengaruhi kebakaran hutan di Indonesia dan implikasi kebijakannya. Jurnal Sylva Lestari, 3(1), 103-112

Juliani, J. (2018). KEBAKARAN HUTAN DI INDONESIA DAN PROSES PENEGAKAN HUKUM SEBAGAI KOMITMEN DALAM MENGATASI DAMPAK PERUBAHAN IKLIM. VERITAS, 4(1), 142-169.

Nababan, Z. A. H., Arisanty, D., \& Mattiro, S. (2021, February). Human, Space, and Environment: Literature Review Through Exploring the Theme in Social Studies. In The 2nd International Conference on Social Sciences Education (ICSSE 2020) (pp. 163-166). Atlantis Press.

Mutiani, M. (2017). IPS dan Pendidikan Lingkungan: Urgensi Pengembangan Sikap Kesadaran Lingkungan Peserta Didik. SOSIO-DIDAKTIKA: Social Science Education Journal, 48-50.

Rahman, A. M., Mutiani, M., \& Putra, M. A. (2019). Pengaruh Kompetensi Pedagogik Dosen terhadap Motivasi Belajar Mahasiswa Pendidikan IPS. Jurnal Darussalam: Jurnal Pendidikan, Komunikasi, Dan Pemikiran Hukum Islam, 378.

Rahmini, N., \& Sofiana, Y.(2021). DAMPAK EKONOMI KARHUTLA DI PROVINSI KALIMANTAN SELATAN (TELAAH KUALITATIF PADA KEBAKARAN LAHAN DI KECAMATAN GAMBUT KALIMANTAN SELATAN). In PROSIDING SEMINAR NASIONAL LINGKUNGAN LAHAN BASAH (Vol. 6, No. 1). 
Rasyid, F. (2019). Permasalahan dan dampak kebakaran hutan. Jurnal Lingkar Widyaiswara, 1(4), 47-59.

Riyani, R., Fahrurazi, F., \& Ariyanto, E. (2020). Fenomena Kejadian Kebakaran Lahan dan Hutan di Kabupaten Tanah Laut (Studi Kualitatif di BPBD Kabupaten Tanah Laut). Doctoral dissertation Universitas Islam Kalimantan MAB.

Sabrina, A. M. (2016). Strategi Pencegahan dan Penanggulangan Kebakaran Hutan dan Lahan. Al-Mabsut: Jurnal Studi Islam dan Sosial, 9(1), 119-130.

Septianingrum, R. (2018). Dampak kebakaran hutan di Indonesia tahun 2015 dalam kehidupan masyarakat. Agric Ecosyst Environ, 1(82), 129-137.

Tuhulele, P. T. (2019). Kebakaran Hutan di Indonesia dan Proses Penegakan Hukumnya Sebagai Komitmen dalam Mengatasi Dampak Perubahan Iklim. Supremasi Hukum: Jurnal Kajian Ilmu Hukum, 3(2).

Yusuf, A., Hapsoh, H., Siregar, S. H., \& Nurrochmat, D. R. (2018). Analisis Kebakaran Hutan Dan Lahan Di Provinsi Riau. Dinamika Lingkungan Indonesia, 6(2), 6784. 